\title{
Substituent Effects on the Inclusion of 1-Alkyl-6-alkoxy-quinolinium in 4-Sulfonatocalix[n]arenes
}

\author{
Véronique Wintgens, ${ }^{\dagger}$ Cédric Lorthioir, ${ }^{\ddagger}$ Zsombor Miskolczy, ${ }^{\S}$ Catherine Amiel, ${ }^{\dagger}$ and László Biczók ${ }^{*}, \odot$ \\ ${ }^{\dagger}$ Université Paris Est, ICMPE (UMR 7182), CNRS, UPEC, 2 rue Henri Dunant, F 94320 Thiais, France \\ ‡Sorbonne Université, CNRS, Collège de France, Laboratoire de Chimie de la Matière Condensée de Paris (LCMCP), 4 Place \\ Jussieu, 75005 Paris, France \\ ${ }^{\S}$ Institute of Materials and Environmental Chemistry, Research Centre for Natural Sciences, Hungarian Academy of Sciences, P.O. \\ Box 286, 1519 Budapest, Hungary
}

\section{Supporting Information}

ABSTRACT: The effect of the chain length of the alkyl and alkoxy substituents on the binding characteristics of 1-alkyl-6alkoxy-quinolinium cations was studied using 4sulfonatocalix[4]arene (SCX4) and 4-sulfonatocalix[6] arene (SCX6) in neutral aqueous solutions at $298 \mathrm{~K}$. Isothermal calorimetric titrations showed enthalpy-controlled inclusion with 1:1 stoichiometry. The equilibrium constants of complexation were always larger for the confinement in SCX4 than in its SCX6 homologue because the better matching between the host and guest sizes allowed more

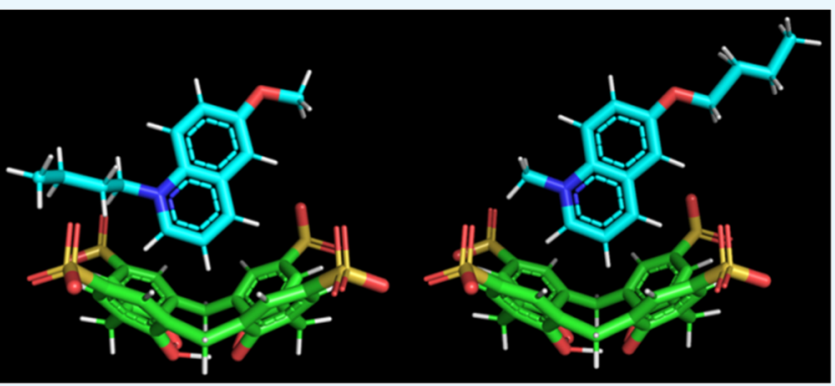
exothermic interaction. The binding affinity diminished with the lengthening of the aliphatic chain of the guests in the case of the association with SCX4, but insignificant change was found for SCX6 complexes. The most substantial change in the enthalpic and entropic contributions to the driving force of complex production occurred when the alkyl chain was linked to the heterocyclic nitrogen and the number of its carbon atoms varied between 1 and $4 .{ }^{1} \mathrm{H}$ NMR spectra evidenced that in SCX6, the 1-alkyl-6-alkoxy-quinolinium cations could be included within the macrocycle cavity. In the case of SCX4, the quinolinium ring is always inside the host, but the alkyl chain is included within SCX4 only for a short chain length ( $n$ up to 4 ). In contrast, the alkoxy chain displays a very weak interaction with the cavity irrespective of the length. Because of the outward orientation from the host, the lengthening of the alkoxy substituent of the quinolinium moiety barely influenced the thermodynamics of inclusion in SCX4. Distinct linear enthalpy-entropy correlations were found for the encapsulation in SCX4 and SCX6.

\section{INTRODUCTION}

The biocompatible, highly water-soluble 4-sulfonatocalix[n]arene $(\mathrm{SCX} n)$ macrocycles represent a particularly important and intensely studied family of cavitands because of their capability to produce various supramolecular architectures, ${ }^{1-3}$ fluorescent sensing systems, ${ }^{4-6}$ and host-guest complexes. ${ }^{7,8}$ Their $\pi$-electron-rich, flexible cavity confines various biologically important compounds, ${ }^{9-11}$ drugs, ${ }^{12-14}$ and photochromic substances, ${ }^{15}$ thereby enhancing the solubility and stability of the guests. The binding between surfactants and SCX $n$ can induce association into nanoparticles, ${ }^{16}$ vesicles, ${ }^{17,18}$ or supramolecular micelles. ${ }^{19,20}$ Such self-assemblies have great potential in the design of stimuli-responsive aggregates and drug delivery vehicles. ${ }^{21,22}$

6-Methoxyquinolinium derivatives are important fluorophores because they can be used in aqueous solution in a wide $\mathrm{pH}$ range and emit substantially Stokes-shifted strong fluorescence. Members of this class of compounds were applied as probes for the detection of the intracellular $\mathrm{Cl}^{-}$ levels ${ }^{23-25}$ and the monitoring of $\mathrm{Cl}^{-}$transport across cell membranes. ${ }^{26,27}$ The photophysical behavior and inclusion complex formation of 6-methoxy-1-methylquinolinium $\left(\mathrm{C}_{1} \mathrm{C}_{1} \mathrm{OQ}^{+}\right)$were investigated, ${ }^{28}$ and the substantial change of its fluorescence was used to detect the embedment of a herbicide in 4-sulfonatocalix [4] arene (SCX4). ${ }^{29}$

For the rational design of tailor-made self-assembled systems incorporating SCXn hosts, the deeper understanding of the relationship between the molecular structure of the components and the driving force of encapsulation is of crucial importance. In the present study, we reveal how the systematic variation of the length and the location of the alkyl chain in quinolinium derivatives influence the thermodynamics of binding and the structure of the produced inclusion complex. We focus on two types of guests, 1-methyl-6-alkoxyquinolinium $\left(\mathrm{C}_{1} \mathrm{C}_{n} \mathrm{OQ}^{+}, n=1,2,4,6\right)$ and 1-alkyl-6methoxy-quinolinium $\left(\mathrm{C}_{n} \mathrm{C}_{1} \mathrm{OQ}^{+}, n=1,2,4,6,8\right)$ cations, and the number of sulfonatophenol units in the SCXn cavitands is varied from $n=4$ to 6 . We intend to deal only

Received: April 17, 2018

Accepted: July 9, 2018

Published: August 2, 2018 
with 1:1 inclusion complexes. Therefore, the larger SCX8 homologue, producing associates of various stoichiometries, were not encompassed in the present work. On the basis of the reported deprotonation constants, ${ }^{30}$ we infer that one phenolic $\mathrm{OH}$ of SCX4 dissociated, whereas two phenolic $\mathrm{OH}$ substituents lost protons in 4-sulfonatocalix[6]arene (SCX6) at neutral $\mathrm{pH}$. Therefore, SCX4 and SCX6 had 5 and 8 negative charges under our experimental conditions, respectively. The formulas of the employed compounds are presented in Scheme 1.

\section{Scheme 1. Chemical Formulas of the Guest and Host} Compounds

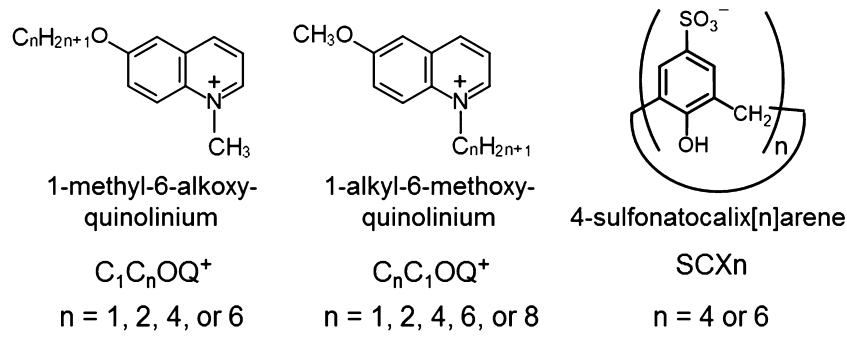

\section{RESULTS AND DISCUSSION}

2.1. Thermodynamics of Inclusion in SCXn. To get insight into the driving force of the confinement of 1-alkyl-6alkoxy-quinolinium $\left(\mathrm{C}_{n} \mathrm{C}_{m} \mathrm{OQ}^{+}\right)$in SCX4 or SCX6 cavitands, isothermal titration calorimetry (ITC) measurements were performed. Figure 1 shows representative results correspond-

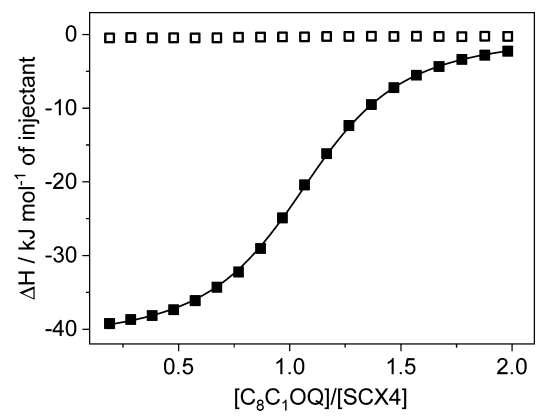

Figure 1. Variation of the integrated heat evolved per injection during the titration of $0.1 \mathrm{mM} \mathrm{SCX} 4$ solution by $2 \mathrm{mM} \mathrm{C}_{8} \mathrm{C}_{1} \mathrm{OQ}^{+}$solution ). The line represents the fit with a $1: 1$ complexation model, whereas $(\square)$ displays the heat released per injection of the titrant into water. ing to the titration of SCX4 by $\mathrm{C}_{8} \mathrm{C}_{1} \mathrm{OQ}^{+}$and the determination of the dilution enthalpy of the titrant. The released heat decreased upon successive additions of the ligand until the value of the dilution heat was reached because of the gradual reduction of the amount of the free binding sites. The inflexion point appeared at the equimolar component concentration, indicating the 1:1 stoichiometry of the resulting complex. The nonlinear least-squares fit of the enthalpograms provided the binding constant $(K)$ and the enthalpy change upon encapsulation $(\Delta H)$. The standard free enthalpy $(\Delta G)$ and entropy changes $(\Delta S)$ were deduced on the basis of the following equation

$$
\Delta G=-R T \ln K=\Delta H-T \Delta S
$$

where $R$ is the gas constant and $T$ stands for the temperature.

Similar experiments were carried out with various $\mathrm{C}_{n} \mathrm{C}_{m} \mathrm{OQ}^{+}-\mathrm{SCX} n$ pairs, and the results are summarized in Table 1. All quinolinium derivatives display larger binding affinity to SCX4 than to SCX6 because the tighter fit into the smaller and more rigid homologue results in more exothermic (6-7 $\mathrm{kJ} \mathrm{mol}^{-1}$ difference) host-guest interactions. The better match of the size of the guests with the cavity of SCX4 ensures the more efficient limitation of the degrees of freedom of the components resulting in more substantial entropy diminution $\left(2-4 \mathrm{~kJ} \mathrm{~mol}^{-1} \mathrm{~T} \Delta S\right.$ difference) for the encapsulation in SCX4.

Figure 2 depicts the correlations between the binding constants and the number of carbon atoms in the aliphatic

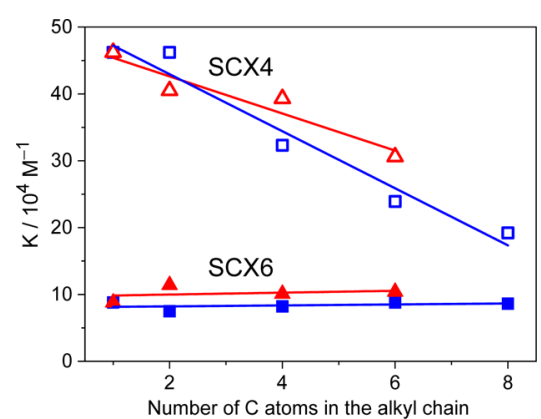

Figure 2. Equilibrium constants for the complexation of $\mathrm{C}_{n} \mathrm{C}_{1} \mathrm{OQ}^{+}$ (squares) or $\mathrm{C}_{1} \mathrm{C}_{n} \mathrm{OQ}^{+}$(triangles) with $\mathrm{SCX} 4$ (empty symbols) and SCX6 (filled symbols) as a function of the number of carbon atoms in the aliphatic chain of the guests at $\mathrm{pH} 7$ and $298 \mathrm{~K}$.

chain of the guest molecules. Decreasing trends were observed when SCX4 served as a host, and the extent of this variation was more pronounced for the $\mathrm{C}_{n} \mathrm{C}_{1} \mathrm{OQ}^{+}$class of compounds

Table 1. Binding Constants and Thermodynamic Parameters for Inclusion Complex Formation in Neutral Aqueous Solution at $298 \mathrm{~K}$

\begin{tabular}{|c|c|c|c|c|c|c|c|c|}
\hline \multirow[b]{2}{*}{ Guest } & \multicolumn{4}{|c|}{ SCX4 } & \multicolumn{4}{|c|}{ SCX6 } \\
\hline & $K, 10^{4} \mathrm{M}^{-1}$ & $\Delta G, \mathrm{~kJ} \mathrm{~mol}^{-1}$ & $\Delta H, \mathrm{~kJ} \mathrm{~mol}^{-1}$ & $T \Delta S, \mathrm{~kJ} \mathrm{~mol}^{-1}$ & $K, 10^{4} \mathrm{M}^{-1}$ & $\Delta G, \mathrm{~kJ} \mathrm{~mol}^{-1}$ & $\Delta H, \mathrm{~kJ} \mathrm{~mol}^{-1}$ & $T \Delta S, \mathrm{~kJ} \mathrm{~mol}{ }^{-1}$ \\
\hline $\mathrm{C}_{1} \mathrm{C}_{1} \mathrm{OQ}^{+} \mathrm{I}^{-}$ & $46.2 \pm 1.8$ & -32.4 & $-38.7 \pm 0.4$ & -6.3 & $8.8 \pm 0.4$ & -28.3 & $-32.1 \pm 0.3$ & -3.8 \\
\hline $\mathrm{C}_{2} \mathrm{C}_{1} \mathrm{OQ}^{+} \mathrm{Br}^{-}$ & $46.2 \pm 1.8$ & -32.4 & $-40.7 \pm 0.4$ & -8.3 & $7.5 \pm 0.3$ & -27.8 & $-33.4 \pm 0.3$ & -5.6 \\
\hline $\mathrm{C}_{4} \mathrm{C}_{1} \mathrm{OQ}^{+} \mathrm{I}^{-}$ & $32.3 \pm 1.3$ & -31.5 & $-42.6 \pm 0.4$ & -11.1 & $8.2 \pm 0.4$ & -28.1 & $-35.6 \pm 0.4$ & -7.5 \\
\hline $\mathrm{C}_{6} \mathrm{C}_{1} \mathrm{OQ}^{+} \mathrm{Br}^{-}$ & $23.9 \pm 1.0$ & -30.7 & $-41.6 \pm 0.4$ & -10.9 & $8.8 \pm 0.4$ & -28.3 & $-35.8 \pm 0.4$ & -7.5 \\
\hline $\mathrm{C}_{8} \mathrm{C}_{1} \mathrm{OQ}^{+} \mathrm{Br}^{-}$ & $19.2 \pm 0.8$ & -30.4 & $-41.7 \pm 0.4$ & -11.3 & $8.6 \pm 0.3$ & -28.2 & $-35.6 \pm 0.4$ & -7.4 \\
\hline $\mathrm{C}_{1} \mathrm{C}_{1} \mathrm{OQ}^{+} \mathrm{I}^{-}$ & $46.2 \pm 1.8$ & -32.4 & $-38.7 \pm 0.4$ & -6.3 & $8.8 \pm 0.4$ & -28.3 & $-32.1 \pm 0.3$ & -3.8 \\
\hline $\mathrm{C}_{1} \mathrm{C}_{2} \mathrm{OQ}^{+} \mathrm{I}^{-}$ & $40.5 \pm 1.6$ & -32.0 & $-37.8 \pm 0.4$ & -5.8 & $11.4 \pm 0.5$ & -28.9 & $-33.3 \pm 0.3$ & -4.5 \\
\hline $\mathrm{C}_{1} \mathrm{C}_{4} \mathrm{OQ}^{+} \mathrm{I}^{-}$ & $39.3 \pm 1.6$ & -32.0 & $-37.8 \pm 0.4$ & -5.8 & $10.1 \pm 0.4$ & -28.6 & $-30.1 \pm 0.3$ & -1.5 \\
\hline $\mathrm{C}_{1} \mathrm{C}_{6} \mathrm{OQ}^{+} \mathrm{I}^{-}$ & $30.6 \pm 1.2$ & -31.3 & $-37.8 \pm 0.4$ & -6.5 & $10.4 \pm 0.4$ & -28.6 & $-28.8 \pm 0.3$ & -0.2 \\
\hline
\end{tabular}


than for the $\mathrm{C}_{1} \mathrm{C}_{n} \mathrm{OQ}^{+}$family. In contrast, the $K$ values of SCX6 complexes were practically independent of the length of the alkyl group because the entropy contribution counterbalanced the $\Delta H$ variation in the series of compounds (Table 1 ). The binding constants of the $\mathrm{C}_{n} \mathrm{C}_{m} \mathrm{OQ}^{+}$embedment in SCX4 were significantly larger than the corresponding values reported for 1-methyl-3-alkylimidazolium ${ }^{31}\left(\mathrm{C}_{n} \mathrm{mim}^{+}\right)$and alkylammonium $^{32}\left(\mathrm{C}_{n} \mathrm{NH}_{3}^{+}\right)$guests. For these guests, the increase of the hydrophobicity and aromatic character follows this order: $\mathrm{C}_{n} \mathrm{NH}_{3}{ }^{+}<\mathrm{C}_{n} \mathrm{mim}^{+}<\mathrm{C}_{n} \mathrm{C}_{m} \mathrm{OQ}^{+}$. In particular, the quinolinium derivatives participate in the strongest hydrophobic host-guest interactions and additionally, are able to interact via $\pi-\pi$ binding between the aromatic ring of the guest and the $\pi$-electron-rich core of SCX4. These two interactions will both contribute to the $\Delta H$ diminution. Indeed, the removal of a weaker-bound hydration shell from the cationic moiety in the course of host-guest complexation requires less desolvation energy for $\mathrm{C}_{n} \mathrm{C}_{m} \mathrm{OQ}^{+}$. The more substantial binding affinity of $\mathrm{C}_{n} \mathrm{C}_{m} \mathrm{OQ}^{+}$cations to SCX4 compared with that of $\mathrm{C}_{n} \mathrm{mim}^{+}$and $\mathrm{C}_{n} \mathrm{NH}_{3}{ }^{+}$arises from the larger enthalpy gain. For example, the $\Delta H$ values of SCX4 complex formation at $298 \mathrm{~K}$ are $-17.9,-33.9$, and $-37.9 \mathrm{~kJ}$ $\mathrm{mol}^{-1}$ for $\mathrm{C}_{4} \mathrm{NH}_{3}^{+}, \mathrm{C}_{4} \mathrm{mim}^{+}$, and $\mathrm{C}_{1} \mathrm{C}_{4} \mathrm{OQ}^{+}$, respectively, whereas the $\Delta S$ values of these processes are 16.6, -19.0 and $-19.5 \mathrm{~J} \mathrm{~mol}^{-1} \mathrm{~K}^{-1}$, respectively. ${ }^{31,32}$ In the case of the confinement in SCX6, $\mathrm{C}_{n} \mathrm{C}_{m} \mathrm{OQ}^{+}$cations had about 1 order of magnitude larger binding constant than $\mathrm{C}_{n} \mathrm{mim}^{+}$guests ${ }^{31}$ because of the less negative $\Delta S$ for the encapsulation of the former class of compounds.

The enthalpy-driven exothermic formation of all $\mathrm{C}_{n} \mathrm{C}_{m} \mathrm{OQ}^{+}$ complexes were accompanied by unfavorable entropy change, implying that the release of water from the hydrate shell of the constituents upon association does not counterbalance the loss of entropy due to the inclusion of the guest in the host cavity. The variation of the enthalpy and entropy terms with the alkyl substituent significantly differed for $\mathrm{C}_{n} \mathrm{C}_{1} \mathrm{OQ}^{+}-\mathrm{SCX} 4$ and $\mathrm{C}_{1} \mathrm{C}_{n} \mathrm{OQ}^{+}-\mathrm{SCX} 4$ (Figure $\mathrm{S} 1$ ). In the case of the former complexes, the gradual lengthening of the carbon chain from methyl to butyl led to $\Delta H$ and $T \Delta S$ reduction, but the change levelled off upon further extension of the aliphatic group. In contrast, $\Delta H$ and $T \Delta S$ were practically independent of the molecular structure of $\mathrm{C}_{1} \mathrm{C}_{n} \mathrm{OQ}^{+}-\mathrm{SCX} 4$, but both quantities increased with the alkyl length for the encapsulation of $\mathrm{C}_{1} \mathrm{C}_{n} \mathrm{OQ}^{+}$in SCX6. The thermodynamic parameters of $\mathrm{C}_{n} \mathrm{C}_{1} \mathrm{OQ}^{+}$embedment in SCX4 followed a similar trend to that found for the inclusion in SCX6. The latter cavitand may adopt inverted double partial cone conformation. ${ }^{33}$ The manner of $\mathrm{C}_{n} \mathrm{C}_{1} \mathrm{OQ}^{+}$inclusion in the partial cone of SCX6 probably resembles the location in SCX4.

We found two distinct linear correlations when the entropy variation of the SCX4 and SCX6 complexes of quinolinium derivatives $(T \Delta S)$ was plotted as a function of the binding enthalpy $(\Delta H)$ (Figure 3). The experimental data were fitted by the following relationship ${ }^{34}$

$$
T \Delta S=\alpha \Delta H+T \Delta S_{0}
$$

where the slope $(\alpha)$ indicates the extent to which the enthalpy change is counterbalanced by the concomitant entropy loss upon complex formation.

Enthalpy-entropy compensation has been observed for host-guest binding ${ }^{35-38}$ because the exothermicity of association usually restricts the movement of the constituents, thereby causing growing entropy loss. In the case of the

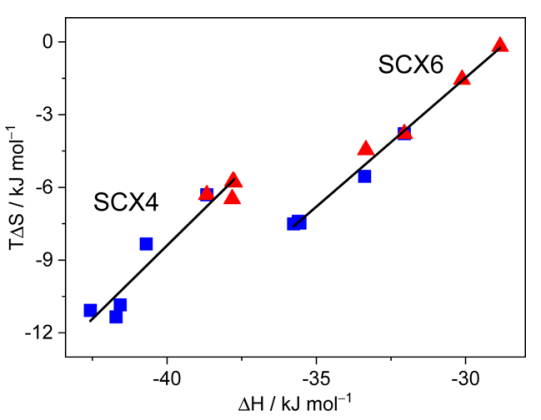

Figure 3. Enthalpy-entropy correlation for the 1:1 inclusion of $\mathrm{C}_{n} \mathrm{C}_{1} \mathrm{OQ}^{+}$(blue square) or $\mathrm{C}_{1} \mathrm{C}_{n} \mathrm{OQ}^{+}$(red triangle) in $\mathrm{SCX} 4$ or SCX6 in neutral aqueous solution at $298 \mathrm{~K}$.

confinement in SCX4, $\alpha=1.21$ and $T \Delta S_{0}=40.0 \mathrm{~kJ} \mathrm{~mol}^{-1}$ were calculated, whereas $\alpha=1.06$ and $T \Delta S_{0}=30.4 \mathrm{~kJ} \mathrm{~mol}^{-1}$ were derived from the thermodynamic data of SCX6 complexes. The larger slope $(\alpha)$ and intercept $\left(T \Delta S_{0}\right)$ of the linear $\Delta H$ versus $T \Delta S$ relationship for the confinement in the smaller SCX4 cavitand is due to the tighter binding and the release of more water molecules from the solvation shell of the reactants than in the case of the association with SCX6. The parameters found for $\mathrm{C}_{n} \mathrm{C}_{m} \mathrm{OQ}^{+}-\mathrm{SCX} 4$ complexes in the present study resemble those reported for the embedment of $\mathrm{C}_{n} \mathrm{mim}^{+}$cations in SCX4 $\left(\alpha=1.38\right.$ and $T \Delta S_{0}=40.3 \mathrm{~kJ}$ $\left.\mathrm{mol}^{-1}\right) .{ }^{31}$ In the case of SCX6 host, $\alpha$ and $T \Delta S_{0}$ for the inclusion of $\mathrm{C}_{n} \mathrm{C}_{m} \mathrm{OQ}^{+}$guests were larger than those found for $\mathrm{C}_{n} \operatorname{mim}^{+}\left(\alpha=0.80\right.$ and $\left.T \Delta S_{0}=16.6 \mathrm{~kJ} \mathrm{~mol}^{-1}\right){ }^{31}$ and approached the values previously found for $1: 1 \mathrm{C}_{n} \mathrm{mim}^{+}-$ SCX8 associates $\left(\alpha=0.96\right.$ and $\left.T \Delta S_{0}=27.9 \mathrm{~kJ} \mathrm{~mol}^{-1}\right) .{ }^{39}$ The much larger $T \Delta S_{0}$ of $\mathrm{C}_{n} \mathrm{C}_{m} \mathrm{OQ}^{+}-\mathrm{SCX} 6$ complexes relative to that of $\mathrm{C}_{n} \mathrm{mim}^{+}-\mathrm{SCX} 6$ implies that more water molecules are expelled from the host interior upon the entry of the bulkier, more hydrophobic quinolinium headgroup. The looser binding of the smaller methylimidazolium moiety causes less extensive desolvation and as a consequence, smaller entropy gain contribution. The close to unity $\alpha$ of $\mathrm{C}_{n} \mathrm{C}_{m} \mathrm{OQ}^{+}-\mathrm{SCX} 6$ complexes indicates that the change of $\Delta H$, arising from the variation of the substitution pattern of the guest, is almost completely offset by the accompanying entropy modification. When the smaller, more hydrophilic headgroup of $\mathrm{C}_{n} \mathrm{mim}^{+}$is encapsulated in SCX6, fewer degrees of freedom are limited and less water is released from the hydrate shell of the constituents into the bulk solution. As a consequence, $\Delta S$ changes in a smaller extent in the series of $\mathrm{C}_{n} \mathrm{mim}^{+}-\mathrm{SCX} 6$ complexes than upon the inclusion of $\mathrm{C}_{n} \mathrm{C}_{m} \mathrm{OQ}^{+}$in SCX6.

2.2. Molecular Structure of the SCXn Complexes. To gain insight into the structure of the inclusion complexes, ${ }^{1} \mathrm{H}$ NMR experiments were performed. As a representative example, Figure 4 displays the spectra of $\mathrm{C}_{4} \mathrm{C}_{1} \mathrm{OQ}^{+}-\mathrm{SCX} 4$ and $\mathrm{C}_{1} \mathrm{C}_{4} \mathrm{OQ}^{+}-\mathrm{SCX} 4$. The broadening observed for the peaks related to the SCX4 protons results from conformational changes of the macrocycle that could correspond to inversions of the aromatic rings ${ }^{40}$ and/or distortions of the cone conformation. ${ }^{41}$ These dynamical processes stand in the intermediate regime, as can be seen in Figure 4. In contrast, the same spectra suggest that both quinolinium derivatives undergo a fast exchange between the free and the complexed states over the characteristic NMR time scale. When the SCX4/quinolinium molar ratio is set to $2: 1$ and the total concentration of $10 \mathrm{mM}$ is used, more than $95 \%$ of the quinolinium derivatives is complexed to SCX4 on the basis of 


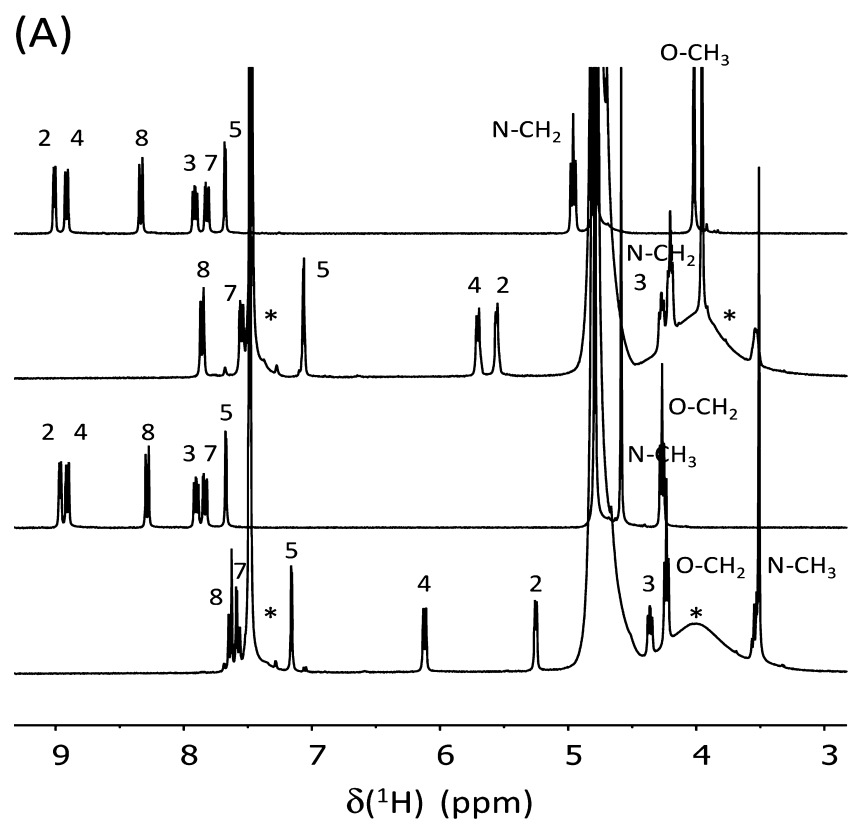

(B)

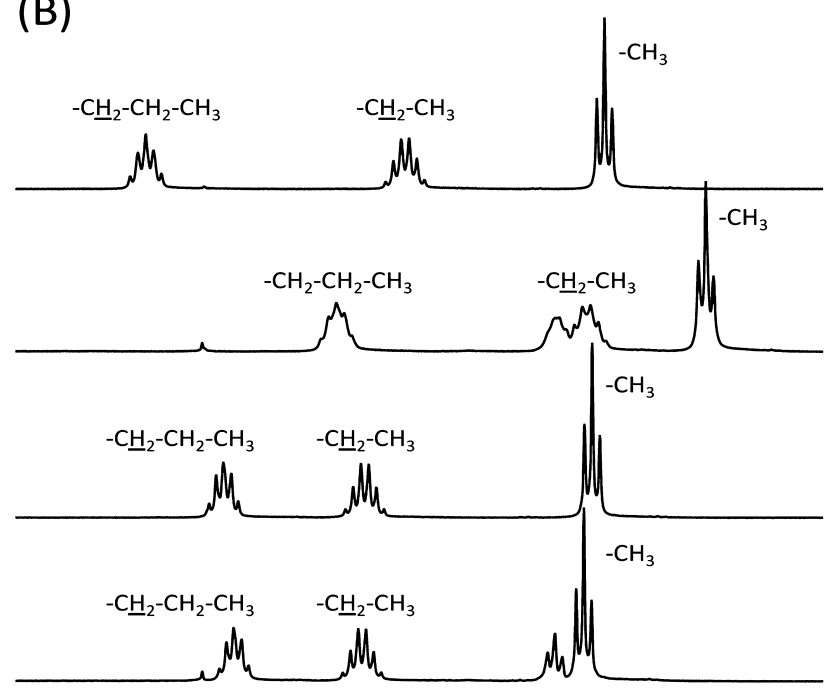

\section{$\begin{array}{lllllllll}2.2 & 2.0 & 1.8 & 1.6 & 1.4 & 1.2 & 1.0 & 0.8 & 0.6\end{array}$ $\delta\left({ }^{1} \mathrm{H}\right)(\mathrm{ppm})$}

Figure 4. From top to bottom: ${ }^{1} \mathrm{H}$ NMR spectra of $10 \mathrm{mM}$ $\mathrm{C}_{4} \mathrm{C}_{1} \mathrm{OQ}^{+}, 3.3 \mathrm{mM} \mathrm{C}_{4} \mathrm{C}_{1} \mathrm{OQ}^{+}+6.7 \mathrm{mM} \mathrm{SCX} 4$ mixture, $10 \mathrm{mM}$ $\mathrm{C}_{1} \mathrm{C}_{4} \mathrm{OQ}^{+}$, and $3.3 \mathrm{mM} \mathrm{C}_{1} \mathrm{C}_{4} \mathrm{OQ}^{+}+6.7 \mathrm{mM}$ SCX4 mixture in $\mathrm{D}_{2} \mathrm{O}$ at $298 \mathrm{~K}$. The asterisks denote the peaks related to the SCX4 protons; $(\mathrm{A}, \mathrm{B})$ correspond to two distinct spectral ranges. The small triplet at $1.05 \mathrm{ppm}$ results from an impurity present in the SCX 4 compound. (The spectrum of neat SCX4 solution displays this small contribution.)

the $K$ value (Table 1 ). Therefore, the ${ }^{1} \mathrm{H}$ chemical shifts measured under such conditions allow the probing of the quinolinium location within both $\mathrm{C}_{4} \mathrm{C}_{1} \mathrm{OQ}^{+}-\mathrm{SCX} 4$ and $\mathrm{C}_{1} \mathrm{C}_{4} \mathrm{OQ}^{+}-\mathrm{SCX} 4$ complexes. In the case of the former complex, the resonances related to the quinolinium and the butyl protons shift upfield in comparison to the signals of the free $\mathrm{C}_{4} \mathrm{C}_{1} \mathrm{OQ}^{+}$molecules. Figure $5 \mathrm{~A}$ and Table $\mathrm{S} 1$ show that the most significant encapsulation-induced chemical shift variations $(\Delta \delta)$ are observed for the peaks assigned to $\mathrm{H} 2$, $\mathrm{H} 3$, and $\mathrm{H} 4$ for all studied guests. This indicates that the
(A)

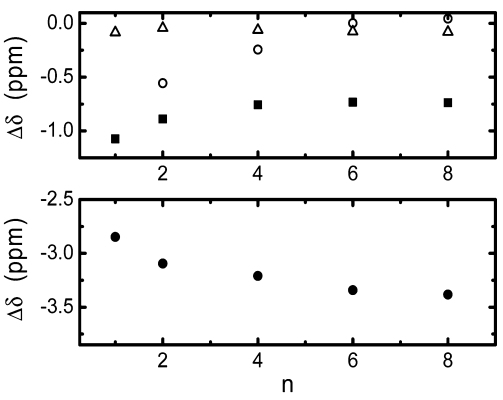

(B)

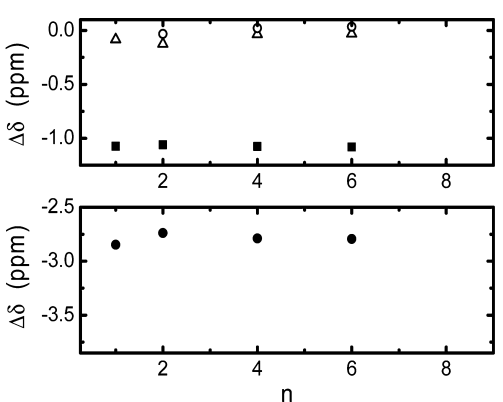

Figure 5. Alkyl chain length $(n)$ dependence of the ${ }^{1} \mathrm{H}$ chemical shift variation upon complex formation for $(A) \mathrm{C}_{n} \mathrm{C}_{1} \mathrm{OQ}^{+}-\mathrm{SCX} 4: \mathrm{NCH}_{2}$ $(\boldsymbol{\square}), \mathrm{H} 4(\mathbf{\bullet}), \mathrm{CH}_{3}(\mathrm{O}), \mathrm{OCH}_{3}(\triangle)$ and $(\mathrm{B}) \mathrm{C}_{1} \mathrm{C}_{n} \mathrm{OQ}^{+}-\mathrm{SCX} 4$ : $\mathrm{NCH}_{3}(\boldsymbol{\square}), \mathrm{H} 4(\bullet), \mathrm{CH}_{3}(\mathrm{O}), \mathrm{OCH}_{2}(\triangle)$. Both complexes are obtained using 1:2 quinolinium/SCX4 molar ratio and a total concentration of $10 \mathrm{mM}$.

corresponding part of the quinolinium has the deepest immersion within the SCX4 cavity. Among the aromatic proton resonances, the $\mathrm{H} 7$ signal undergoes the weakest upfield shift, implying that this terminal of the quinolinium is oriented toward the aqueous phase. The $\Delta \delta$ value determined for the methoxy protons is the smallest in $\mathrm{C}_{n} \mathrm{C}_{1} \mathrm{OQ}^{+}-\mathrm{SCX} 4$ complexes, indicating that the methoxy substituent is located far from the core of the macrocycle.

Among the alkyl protons of $\mathrm{C}_{n} \mathrm{C}_{1} \mathrm{OQ}^{+}$, the increase of the alkyl chain length resulted in the largest chemical shift variation for the $-\mathrm{CH}_{3}$ protons. As shown in Figure $5 \mathrm{~A}$, the $\Delta \delta$ value of this signal is reduced upon the gradual increase of the number of aliphatic carbon atoms from methyl to hexyl, while the change tends to level off for $\mathrm{C}_{n} \mathrm{C}_{1} \mathrm{OQ}^{+}-\mathrm{SCX} 4$ with $n \geq 6$. Such a behavior suggests that the short alkyl chains $(n=1,2$, and 4) were included in SCX4. Hexyl and octyl substituents are too long to be fully embedded in SCX4. Therefore, their end is located outside the cavity, exhibiting vanishing interactions with the host. This is in accord with the results of the calorimetric experiments (Table 1), which demonstrated that the exothermicity of inclusion in SCX4 initially grew upon the gradual increase of the number of aliphatic carbon atoms in the substituent linked to the heterocyclic nitrogen and then levelled off. The incorporation of the short alkyl chains $(n<6)$ within the macrocycle may rationalize the line broadening observed for their ${ }^{1} \mathrm{H}$ NMR peaks in the spectrum of $\mathrm{C}_{n} \mathrm{C}_{1} \mathrm{OQ}^{+}-\mathrm{SCX} 4$, as exemplified for $n=4$ in Figure 4B. The confinement of the aliphatic chains should indeed induce a restriction in their reorientational motions and then, a reduction of their $T_{2}\left({ }^{1} \mathrm{H}\right)$ relaxation times compared to free $\mathrm{C}_{n} \mathrm{C}_{1} \mathrm{OQ}^{+}$.

As the number of carbon atoms in the alkyl chain is raised from $n=1$ to 4 , the $\Delta \delta$ values for the aromatic protons vary. In particular, a continuous increase is observed for $\mathrm{H} 2$ and $\mathrm{H} 8$ 
(and also $\mathrm{NCH}_{2}$ ), whereas the opposite trend is observed for $\mathrm{H} 3$ and $\mathrm{H} 4$. These simultaneous variations suggest an alteration of the orientation of the quinolinium ring within the SCX4 cavity resulting from the increase of the volume occupied by the alkyl chain.

In the case of the $\mathrm{C}_{1} \mathrm{C}_{n} \mathrm{OQ}^{+}-\mathrm{SCX} 4$ complexes, the chemical shift of the ${ }^{1} \mathrm{H}$ NMR peaks related to the alkoxy moiety is nearly unchanged with respect to the value observed for the solution of the corresponding uncomplexed quinolinium (Figure 5B and Table S2). Figure 4 shows that the chemical shift of each proton of the quinolinium ring of $\mathrm{C}_{1} \mathrm{C}_{n} \mathrm{OQ}^{+}$still displays a significant change upon the addition of SCX4. In particular, the peaks attributed to $\mathrm{H} 2, \mathrm{H} 3, \mathrm{H} 4$, and $\mathrm{N}-\mathrm{CH}_{3}$ protons undergo the most significant upfield shift, implying that the quinolinium ring of $\mathrm{C}_{1} \mathrm{C}_{n} \mathrm{OQ}^{+}$is inside the SCX4 cavity, whereas the alkoxy chain protrudes from it. The line width of the ${ }^{1} \mathrm{H}$ NMR peaks assigned to the alkoxy group of $\mathrm{C}_{1} \mathrm{C}_{n} \mathrm{OQ}^{+}-\mathrm{SCX} 4$ is similar to the one observed in the spectrum of free $\mathrm{C}_{1} \mathrm{C}_{n} \mathrm{OQ}^{+}$(Figure $4 \mathrm{~B}$ ). In contrast to $\mathrm{C}_{n} \mathrm{C}_{1} \mathrm{OQ}^{+}-\mathrm{SCX} 4(n<6)$, the aliphatic chain is not confined within the macrocycle and as a result, no significant line broadening is found.

The $\Delta \delta$ values for the protons of the quinolinium moiety of $\mathrm{C}_{1} \mathrm{C}_{n} \mathrm{OQ}^{+}$and $\mathrm{C}_{n} \mathrm{C}_{1} \mathrm{OQ}^{+}$differ for $n \geq 2$ (Figure 5), suggesting distinct orientations of the heterocyclic ring within SCX4. Another main difference between the $\mathrm{C}_{1} \mathrm{C}_{n} \mathrm{OQ}^{+}-\mathrm{SCX} 4$ and the $\mathrm{C}_{n} \mathrm{C}_{1} \mathrm{OQ}^{+}-\mathrm{SCX} 4$ complexes concerns the position of the alkoxy and alkyl chains. In the case of the $\mathrm{C}_{n} \mathrm{C}_{1} \mathrm{OQ}^{+}-\mathrm{SCX} 4$ complexes, the alkyl chains may be included within the SCX4 host for low $n$ values $(n<6)$. As $n$ is raised further, the alkyl chain end extends out of the cavity. This could result from a contribution of steric hindrance. In contrast, for the $\mathrm{C}_{1} \mathrm{C}_{n} \mathrm{OQ}^{+}-\mathrm{SCX} 4$ complexes, the shortest alkoxy group $(n=$ 1) is already far from the interior of the host. Therefore, the increase of this chain length does not cause any $\Delta \delta$ change (Figure 5B) and the orientation of the quinolinium ring of $\mathrm{C}_{1} \mathrm{C}_{n} \mathrm{OQ}^{+}-\mathrm{SCX} 4$ remains unaltered. The outward orientation from the host cavity rationalizes that the lengthening of the alkoxy substituent brings about minor change in $\Delta H$ and $\Delta S$ of $\mathrm{C}_{1} \mathrm{C}_{n} \mathrm{OQ}^{+}-\mathrm{SCX} 4$ complex formation (Table 1).

Because of the lower binding affinity to SCX6, ${ }^{1} \mathrm{H}$ NMR spectra were recorded for a 1:3 quinolinium/SCX6 molar ratio to ensure that more than $95 \%$ of the guest was confined to the host. The variations of the proton chemical shifts $(\Delta \delta)$ upon complexation of $\mathrm{C}_{1} \mathrm{C}_{1} \mathrm{OQ}^{+}$with SCX6 and SCX4 are compared in Table S3 of the Supporting Information. The upfield shift of all ${ }^{1} \mathrm{H}$ NMR peaks upon confinement in SCX6 indicates that the entire $\mathrm{C}_{1} \mathrm{C}_{1} \mathrm{OQ}^{+}$cation is included in the spacious cavity of the host. In the case of the $\mathrm{C}_{1} \mathrm{C}_{1} \mathrm{OQ}^{+}-\mathrm{SCX} 6$ complex, the upfield shift related to the $\mathrm{H} 2, \mathrm{H} 3$, and $\mathrm{H} 4$ signals were significantly smaller because of the looser binding. For the other aromatic protons of the guest, the upfield shift was found to be higher than that of the corresponding peaks in the spectrum of $\mathrm{C}_{1} \mathrm{C}_{1} \mathrm{OQ}^{+}-\mathrm{SCX} 4$. In the larger SCX6 macrocycle, various orientations of the guest could be allowed, leading to an additional averaging of the corresponding ${ }^{1} \mathrm{H}$ chemical shifts.

When a methyl substituent of $\mathrm{C}_{1} \mathrm{C}_{1} \mathrm{OQ}^{+}$was replaced by a butyl group, the chemical shift changes induced by the incorporation into SCX6 remained similar to those of $\mathrm{C}_{1} \mathrm{C}_{1} \mathrm{OQ}^{+}-\mathrm{SCX} 6$ and did not depend significantly on the location of the butyl moiety (Table S4, Supporting Information). All butyl proton signals of $\mathrm{C}_{4} \mathrm{C}_{1} \mathrm{OQ}^{+}$and
$\mathrm{C}_{1} \mathrm{C}_{4} \mathrm{OQ}^{+}$shifted upfield, indicating that the whole butyl chain interacts with SCX6. The larger and more flexible SCX6 macrocycle adapts better to the geometrical features of the guests than SCX4. The guest binding induced calixarene conformation change, the so-called "template effect" which has also been noticed for other associates, ${ }^{40,42,43}$ may explain the slightly larger alteration of $\Delta H$ and $\Delta S$ with the substituent in the series of $\mathrm{C}_{1} \mathrm{C}_{n} \mathrm{OQ}^{+}-\mathrm{SCX} 6$ complexes (Table 1 ).

\section{CONCLUSIONS}

The confinement of $\mathrm{C}_{n} \mathrm{C}_{m} \mathrm{OQ}^{+}$in SCXn cavitands significantly depends not only on the location and the length of the hydrocarbon chain of the guest but also on the size of the macrocycle. Both the thermodynamic parameters of the embedment in SCXn and the structure of the resulting $\mathrm{C}_{n} \mathrm{C}_{m} \mathrm{OQ}^{+}-\mathrm{SCX} n$ complexes can be tuned by the variation of the number of aliphatic carbon atoms attached to the nitrogen of the quinolinium moiety, but alteration of the alkoxy chain length causes a minor effect. ${ }^{1} \mathrm{H}$ NMR experiments demonstrated that in the case of SCX4, the short alkyl chains $(n \leq 4)$ may be incorporated, together with the quinolinium ring, within the host cavity, while a part of longer alkyl chains are located out of the cavity. In contrast, even the short alkoxy groups were found to display very weak interactions with SCX4, while the quinolinium ring is still found within the cavity. The larger SCX6 macrocycle allows an easier inclusion of both kinds of quinolinium $\left(\mathrm{C}_{n} \mathrm{C}_{1} \mathrm{OQ}^{+}\right.$and $\left.\mathrm{C}_{1} \mathrm{C}_{m} \mathrm{OQ}^{+}\right)$, with an incorporation of either the alkyl or the alkoxy chains within the cavity when $n$ or $m \leq 4$. From a thermodynamic point of view, the tighter binding in the smaller, more rigid SCX4 brings about larger enthalpy gain accompanied by more substantial entropy diminution, which lead to considerably larger equilibrium constant than the association with SCX6. The stability of the $\mathrm{C}_{n} \mathrm{C}_{m} \mathrm{OQ}^{+}-\mathrm{SCX} 6$ complexes cannot be modified by the alteration of the alkyl substituent of the guest because the enthalpy variation is compensated by the concomitant entropy change. The knowledge on the relationship between the molecular structure of constituents and the thermodynamics of host-guest binding gained in the present study may be applied in the design of tailor-made supramolecular systems and self-assembled architectures.

\section{EXPERIMENTAL SECTION}

4.1. Materials. SCX4 and SCX6 were purchased from Acros Organics and used after drying under vacuum at $343 \mathrm{~K}$ overnight. Double-distilled water was used as a solvent, and $\operatorname{SCX} n(n=4$ or 6$)$ solutions were neutralized by the minimum volume of concentrated $\mathrm{NaOH}$. The various 1-alkyl-6-alkoxyquinolinium salts were synthesized and characterized as described in the Supporting Information. $\mathrm{C}_{1} \mathrm{C}_{n} \mathrm{OQ}^{+}$and $\mathrm{C}_{4} \mathrm{C}_{1} \mathrm{OQ}^{+}$had $\mathrm{I}^{-}$counterions, whereas $\mathrm{C}_{2} \mathrm{C}_{1} \mathrm{OQ}^{+}, \mathrm{C}_{6} \mathrm{C}_{1} \mathrm{OQ}^{+}$, and $\mathrm{C}_{8} \mathrm{C}_{1} \mathrm{OQ}^{+}$were used as $\mathrm{Br}^{-}$salts.

4.2. Sample Preparation. Stock solutions of 1-alkyl-6alkoxy-quinolinium salts $(2 \mathrm{mM})$ and $\mathrm{SCX} n(0.1 \mathrm{mM}$, adjusted to $\mathrm{pH} 7$ by $\mathrm{NaOH}$ addition) were prepared for ITC experiments. NMR experiments were performed by mixing appropriate amounts of 1-alkyl-6-alkoxy-quinolinium (6 or 10 $\mathrm{mM}$ ) and $\mathrm{SCX} n$ ( 6 or $10 \mathrm{mM}$, neutralized by $\mathrm{NaOD}$ ) solutions in $\mathrm{D}_{2} \mathrm{O}$. All the experiments were carried out at $\mathrm{pH} 7$.

4.3. Instrumentation. ${ }^{1} \mathrm{H}$ NMR spectra were recorded in deuterated dimethyl sulfoxide or in $\mathrm{D}_{2} \mathrm{O}$ on a Bruker Avance II $400 \mathrm{MHz}$ NMR spectrometer. ITC measurements were carried 
out with a MicroCal VP-ITC microcalorimeter. Quinolinium solutions were injected from the computer-controlled microsyringe at an interval of $180 \mathrm{~s}$ into the cell (volume $=1.4569$ $\mathrm{mL}$ ) containing $0.1 \mathrm{mM} \mathrm{SCXn}$ solution at $\mathrm{pH} 7$, while stirring at $450 \mathrm{rpm}$.

\section{ASSOCIATED CONTENT}

\section{S Supporting Information}

The Supporting Information is available free of charge on the ACS Publications website at DOI: 10.1021/acsomega.8b00736.

Detailed descriptions of synthesis and ${ }^{1} \mathrm{H}$ NMR spectral characteristics of the studied quinolinium derivatives, molecular structure dependence of the thermodynamic parameters of host-guest complexes, and variation of the ${ }^{1} \mathrm{H}$ NMR chemical shifts upon inclusion complex formation (PDF)

\section{AUTHOR INFORMATION}

\section{Corresponding Author}

*E-mail: biczok.laszlo@ttk.mta.hu (L.B.).

\section{ORCID $\odot$}

László Biczók: 0000-0003-2568-5942

\section{Notes}

The authors declare no competing financial interest.

\section{ACKNOWLEDGMENTS}

This work was supported by the BIONANO GINOP-2.3.2-152016-00017 project (to Z.M. and L.B.), the National Research, Development and Innovation Office (NKFIH, grant K123995 to Z.M. and L.B.), and the János Bolyai Research Scholarship Program of the Hungarian Academy of Sciences (to Z.M.).

\section{REFERENCES}

(1) Atwood, J. L.; Barbour, L. J.; Hardie, M. J.; Raston, C. L. Metal sulfonatocalix $[4,5]$ arene complexes: Bi-layers, capsules, spheres, tubular arrays and beyond. Coord. Chem. Rev. 2001, 222, 3-32.

(2) Liu, Y.; Wang, Y.-X. Selective molecular binding and nanosupramolecular assembly of $p$-sulfonatocalix[n]arenes. Non-Covalent Interactions in the Synthesis and Design of New Compounds; John Wiley \& Sons, Inc., 2016; pp 261-281.

(3) Ling, I.; Alias, Y.; Raston, C. L. Structural diversity of multicomponent self-assembled systems incorporating $p$-sulfonatocalix[4]arene. New J. Chem. 2010, 34, 1802-1811.

(4) Guo, D.-S.; Uzunova, V. D.; Su, X.; Liu, Y.; Nau, W. M. Operational calixarene-based fluorescent sensing systems for choline and acetylcholine and their application to enzymatic reactions. Chem. Sci. 2011, 2, 1722-1734.

(5) Ghale, G.; Nau, W. M. Dynamically analyte-responsive macrocyclic host-fluorophore systems. Acc. Chem. Res. 2014, 47, 2150-2159.

(6) Florea, M.; Kudithipudi, S.; Rei, A.; González-Álvarez, M. J.; Jeltsch, A.; Nau, W. M. A fluorescence-based supramolecular tandem assay for monitoring lysine methyltransferase activity in homogeneous solution. Chem.-Eur. J. 2012, 18, 3521-3528.

(7) Guo, D.-S.; Wang, K.; Liu, Y. Selective binding behaviors of $p$ sulfonatocalixarenes in aqueous solution. J. Inclusion Phenom. Macrocyclic Chem. 2008, 62, 1-21.

(8) Dsouza, R. N.; Pischel, U.; Nau, W. M. Fluorescent dyes and their supramolecular host/guest complexes with macrocycles in aqueous solution. Chem. Rev. 2011, 111, 7941-7980.

(9) Perret, F.; Lazar, A. N.; Coleman, A. W. Biochemistry of the para-sulfonato-calix[n] arenes. Chem. Commun. 2006, 2425-2438.
(10) Perret, F.; Coleman, A. W. Biochemistry of anionic calix[n]arenes. Chem. Commun. 2011, 47, 7303-7319.

(11) Megyesi, M.; Biczók, L. Considerable fluorescence enhancement upon supramolecular complex formation between berberine and p-sulfonated calixarenes. Chem. Phys. Lett. 2006, 424, 71-76.

(12) Mokhtari, B.; Pourabdollah, K. Applications of calixarene nanobaskets in pharmacology. J. Inclusion Phenom. Macrocyclic Chem. 2012, $73,1-15$

(13) Chao, J.; Song, K.; Wang, H.; Guo, Z.; Zhang, B.; Zhang, T. Study on the inclusion interaction of $p$-sulfonatocalix[n]arenes with norfloxacin. Phys. Chem. Liq. 2017, 55, 579-588.

(14) Li, Q.; Guo, D.-S.; Qian, H.; Liu, Y. Complexation of $p$ sulfonatocalixarenes with local anaesthetics guests: Binding structures, stabilities, and thermodynamic origins. Eur. J. Org. Chem. 2012, 3962-3971.

(15) Miskolczy, Z.; Biczók, L. Photochromism of a merocyanine dye bound to sulfonatocalixarenes: Effect of $\mathrm{pH}$ and the size of macrocycle on the kinetics. J. Phys. Chem. B 2013, 117, 648-653.

(16) Harangozó, J. G.; Wintgens, V.; Miskolczy, Z.; Guigner, J.-M.; Amiel, C.; Biczók, L. Effect of macrocycle size on the self-assembly of methylimidazolium surfactant with sulfonatocalix[n]arenes. Langmuir 2016, 32, 10651-10658.

(17) Wang, K.; Guo, D.-S.; Zhao, M.-Y.; Liu, Y. A supramolecular vesicle based on the complexation of $p$-sulfonatocalixarene with protamine and its trypsin-triggered controllable-release properties. Chem.-Eur. J. 2016, 22, 1475-1483.

(18) Francisco, V.; Basilio, N.; Garcia-Rio, L.; Leis, J. R.; Maques, E. F.; Vázquez-Vázquez, C. Novel catanionic vesicles from calixarene and single-chain surfactant. Chem. Commun. 2010, 46, 6551-6553.

(19) Basílio, N.; Spudeit, D. A.; Bastos, J.; Scorsin, L.; Fiedler, H. D.; Nome, F.; García-Río, L. Exploring the charged nature of supramolecular micelles based on $p$-sulfonatocalix[6]arene and dodecyltrimethylammonium bromide. Phys. Chem. Chem. Phys. 2015, 17, 26378-26385.

(20) Wintgens, V.; Miskolczy, Z.; Guigner, J.-M.; Amiel, C.; Harangozó, J. G.; Biczók, L. Reversible nanoparticle-micelle transformation of ionic liquid-sulfonatocalix[6]arene aggregates. Langmuir 2015, 31, 6655-6662.

(21) Guo, D.-S.; Liu, Y. Supramolecular chemistry of $p$ sulfonatocalix[n]arenes and its biological applications. Acc. Chem. Res. 2014, 47, 1925-1934.

(22) Wang, K.; Guo, D.-S.; Wang, X.; Liu, Y. Multistimuli responsive supramolecular vesicles based on the recognition of $p$-sulfonatocalixarene and its controllable release of doxorubicin. ACS Nano 2011, 5, 2880-2894.

(23) Baù, L.; Selvestrel, F.; Arduini, M.; Zamparo, I.; Lodovichi, C.; Mancin, F. A cell-penetrating ratiometric nanoprobe for intracellular chloride. Org. Lett. 2012, 14, 2984-2987.

(24) Inglefield, J. R.; Schwartz-Bloom, R. D. Fluorescence imaging of changes in intracellular chloride in living brain slices. Methods 1999, 18, 197-203.

(25) Schwartz, R. D.; Yu, X. Optical imaging of intracellular chloride in living brain slices. J. Neurosci. Methods 1995, 62, 185-192.

(26) Illsley, N. P.; Verkman, A. S. Membrane chloride transport measured using a chloride-sensitive fluorescent probe. Biochemistry 1987, 26, 1215-1219.

(27) Hennig, B.; Schultheiss, G.; Kunzelmann, K.; Diener, M. Ca ${ }^{2+}$ induced $\mathrm{Cl}^{-}$efflux at rat distal colonic epithelium. J. Membr. Biol. 2008, 221, 61-72.

(28) Miskolczy, Z.; Harangozó, J. G.; Biczók, L.; Wintgens, V.; Lorthioir, C.; Amiel, C. Effect of torsional isomerization and inclusion complex formation with cucurbit[7]uril on the fluorescence of 6methoxy-1-methylquinolinium. Photochem. Photobiol. Sci. 2014, 13, 499-508.

(29) Harangozó, J. G.; Miskolczy, Z.; Biczók, L.; Wintgens, V.; Lorthioir, C. Effect of host-guest complex formation on the fluorescence of 6-methoxy-1-methyl-quinolinium cation with 4sulfonatocalix[4]arene: utilization as a fluorescent probe for the 
study of difenzoquat binding. J. Inclusion Phenom. Macrocyclic Chem.

2015, 81, 377-384.

(30) Suga, K.; Ohzono, T.; Negishi, M.; Deuchi, K.; Morita, Y. Effect of various cations on the acidity of $p$-sulfonatocalixarenes. Supramol. Sci. 1998, 5, 9-14.

(31) Wintgens, V.; Biczók, L.; Miskolczy, Z. Thermodynamics of host-guest complexation between $p$-sulfonatocalixarenes and 1-alkyl3-methylimidazolium type ionic liquids. Thermochim. Acta 2011, 523, 227-231.

(32) Stödeman, M.; Dhar, N. Microcalorimetric titration of a tetra- $p$ sulfonated calix[4]arene with alkylammonium ions in aqueous solution. J. Chem. Soc., Faraday Trans. 1998, 94, 899-903.

(33) Atwood, J. L.; Clark, D. L.; Juneja, R. K.; Orr, G. W.; Robinson, K. D.; Vincent, R. L. Double partial cone conformation for $\mathrm{Na}_{8}\{$ calix[6]arene sulfonate $\} \cdot 20.5 \mathrm{H}_{2} \mathrm{O}$ and its parent acid. J. Am. Chem. Soc. 1992, 114, 7558-7559.

(34) Inoue, Y.; Hakushi, T.; Liu, Y.; Tong, L.; Shen, B.; Jin, D. Thermodynamics of molecular recognition by cyclodextrins. 1 . Calorimetric titration of inclusion complexation of naphthalenesulfonates with $\alpha$-, $\beta$-, and $\gamma$-cyclodextrins: enthalpy-entropy compensation. J. Am. Chem. Soc. 1993, 115, 475-481.

(35) Inoue, Y.; Liu, Y.; Tong, L. H.; Shen, B. J.; Jin, D. S. Calorimetric titration of inclusion complexation with modified $\beta$ cyclodextrins. Enthalpy-entropy compensation in host-guest complexation: from ionophore to cyclodextrin and cyclophane. J. Am. Chem. Soc. 1993, 115, 10637-10644.

(36) Rekharsky, M. V.; Inoue, Y. Complexation thermodynamics of cyclodextrins. Chem. Rev. 1998, 98, 1875-1918.

(37) Masson, E.; Ling, X.; Joseph, R.; Kyeremeh-Mensah, L.; Lu, X. Cucurbituril chemistry: A tale of supramolecular success. RSC Adv. 2012, 2, 1213-1247.

(38) Houk, K. N.; Leach, A. G.; Kim, S. P.; Zhang, X. Binding Affinities of Host-Guest, Protein-Ligand, and Protein-Transition-State Complexes. Angew. Chem., Int. Ed. 2003, 42, 4872-4897.

(39) Wintgens, V.; Amiel, C.; Biczók, L.; Miskolczy, Z.; Megyesi, M. Host-guest interactions between 4-sulfonatocalix[8] arene and 1-alkyl3-methylimidazolium type ionic liquids. Thermochim. Acta 2012, 548, 76-80.

(40) Shinkai, S.; Araki, K.; Matsuda, T.; Manabe, O. NMR determination of association constants for aqueous calixarene complexes and guest template effects on the conformational freedom. Bull. Chem. Soc. Jpn. 1989, 62, 3856-3862.

(41) Shinkai, S.; Mori, S.; Koreishi, H.; Tsubaki, T.; Manabe, O. Hexasulfonated calix[6]arene derivatives: A new class of catalysts, surfactants, and host molecules. J. Am. Chem. Soc. 1986, 108, 24092416.

(42) Arimura, T.; Kubota, M.; Araki, K.; Shinkai, S.; Matsuda, T. "Template effects" on calixarene conformations through host-guesttype interactions. Tetrahedron Lett. 1989, 30, 2563-2566.

(43) Shinkai, S.; Araki, K.; Kubota, M.; Arimura, T.; Matsuda, T. Ion template effects on the conformation of water-soluble calixarenes. $J$. Org. Chem. 1991, 56, 295-300. 